\title{
Is Your Time Well Spent? Reflecting on Knowledge Work More Holistically
}

\author{
Hayley Guillou ${ }^{1}$, Kevin Chow ${ }^{1}$, Thomas Fritz ${ }^{2}$, Joanna McGrenere ${ }^{1}$ \\ ${ }^{1}$ University of British Columbia, Vancouver, Canada \\ ${ }^{2}$ University of Zurich, Zurich, Switzerland \\ ${ }^{1}$ \{ guillouh, kchowk, joanna\}@ cs.ubc.ca, ${ }^{2}$ fritz@ifi.uzh.ch
}

\begin{abstract}
The modern workplace is more demanding than ever before. Yet, since the industrial age, productivity measures have predominantly stayed narrowly focused on the output of the work, and not accounted for the big shift in the cognitive demands placed on the workers or the interleaving of work and life that is so common today. We posit that a more holistic conceptualization of Time Well Spent (TWS) at work could mitigate this issue. In our 1-week study, 40 knowledge workers used the experience sampling method (ESM) to rate their TWS and then define TWS at the end of the week. Our work contributes a preliminary characterization of TWS and empirical evidence that this term can capture a more holistic notion of work that also includes the worker's feelings and well-being.
\end{abstract}

\section{Author Keywords}

Knowledge worker; Productivity; Productivity tools; Time tracking; Experience sampling method; Well-being

\section{CCS Concepts \\ -Human-centered computing $\rightarrow$ Empirical studies in HCI;}

\section{INTRODUCTION}

In this age of information, knowledge workers have higher demands than ever before. Industrial workers often had clearly defined and somewhat repetitive tasks that were performed in a defined w orkday w hile largely disconnected from the outside world. In contrast, today's workers, most notably knowledge workers, often have flexible hours and autonomy to perform a broad variety of cognitively demanding tasks. The always-connected nature of technology has fuelled both an interleaving of work and life and an increase in interruptions and distractions at work. These changes to work and the digitization of it have been accompanied by an increase in mental health problems [1,36], so much so that the World Health Organization is raising concerns over workers' mental health. Yet, despite these radical changes, knowledge workers

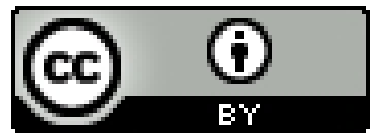

This work is licensed under a Creative Commons Attribution International 4.0 License.

CHI '20, April 25-30, 2020, Honolulu, HI, ÚSA.

(C) 2020 Copyright is held by the owner/author(s).

ACM ISBN 978-1-4503-6708-0/20/04.

http://dx.doi.org/10.1145/3313831.3376586 are often still assessed using classic productivity measures that narrowly focus on the output of their work [38], such as the number of tasks completed, that do not take into account the overall well-being of the worker.

There is a breadth of research that investigates worker productivity in the digital age, but it predominantly focuses separately on either productivity or specific aspects of well-being $[7,21,37]$. For instance, the factors that influence employee productivity have been examined in organizational productivity research (see [17] for a review). More recently in HCI research, knowledge workers' assessment of perceived productivity has been characterized [21]. There are studies that capture emotions during work [25, 31, 32], but none are focused on having individuals themselves explore the effect of emotions on their work and well-being, and vice versa. Other research has devised and examined approaches to foster productivity. For example, by reducing digital distractions, to lower stress through interventions, or by providing technology for self-monitoring for productivity (e.g. [22]) or emotions at work (e.g. [33]). One such study showed specifically that technology interventions to reduce distractions in fact significantly increased some workers' stress [27].

What is missing from the literature, as well as technology interventions in the marketplace (e.g. RescueTime [40]), is a more holistic approach, one that combines classic productivity with well-being, to capture more fully how knowledge workers are doing. We posit that such a holistic approach could be incorporated into the design of digital tools that more effectively support workers. This is our long-term research objective.

The goal of this current paper is to investigate whether we can foster more holistic thinking about a knowledge worker's time at work. By focusing on the notion of "Time Well Spent" (TWS) at work-a term that has also recently appeared in popular media [16] —we hope to capture actions that are both productivity-related and those that are targeted at well-being, as well as workers' perceptions and emotions.

We conducted a one-week study using the experience sampling method (ESM) to investigate whether using the term TWS helps to capture a more holistic notion during primary working hours. We recruited 40 participants and collected their personal definitions of the term TWS and experience samples where they rated the degree to which their time was well spent. Our findings show that people characterize TWS 
in terms of what they work on, how they work, how they feel, and how they take care of themselves. Importantly, we show that the term Time Well Spent evokes a strong theme of Self Care. Additionally, some participants who reflected on both activities and emotions changed their perception of their work.

Our paper contributes a preliminary characterization of TWS and empirical evidence that this term can capture a holistic notion of work. We show that when knowledge workers reflect on TWS during working hours, the importance of self care and how one feels is emphasized. We offer concrete ideas for future work with an ESM intervention that will more explicitly capture the emotional component of work using TWS.

\section{RELATED WORK}

We begin by discussing productivity as the current performance metric for work and review the limitations of current self-monitoring technologies that promote productive work. We then discuss stress in the workplace and how health behaviours are being tracked.

\section{Productivity and Self-Tracking}

Productivity is the primary work performance measure today, but this term is becoming harder to define as a majority of the workforce has gone from labourers with relatively straightforward inputs and tangible outputs to creative knowledge workers with domain specific and hard-to-quantify outputs. Research has identified a variety of factors that influence productivity for knowledge workers. These factors include organizational ones, such as team dynamics [5], feedback [12], autonomy [12, 42], and office environments [7, 18]. At the same time, there are various personal factors that influence workers' productivity, such as intrinsic motivation [15], psychological well-being [7, 43, 46], work engagement [3, 47].

The HCI community has been targeting several of these productivity factors in today's technology-rich work environments. For instance, researchers extensively studied the nature of distractions/interruptions and devised approaches to lower their burden on productivity [4, 10, 11, 19, 27, 28, 29]. However, a concern with some productivity enhancing methods is that they can cause an increase in stress, for example, by negatively framing productivity [22] or by blocking distractions for individuals who were already focused at work [27].

There is also a growing body of HCI research that focuses on quantifying aspects of work and promoting more productive work behaviors by the use of self-monitoring techniques. Most of the existing self-monitoring software tools use automated tracking to determine productivity and focus on the time spent in computer applications [22, 45, 40]. While this reduces the burden of data collection for the user, only capturing the activity (such as website or application in use) and duration may fail to recognize the context of the activity and even if the activity was related to work, it cannot accurately judge whether this time was spent efficiently. Also, automated tracking can only detect activities on the system where the software is installed, so real-life activities, such as face-to-face conversations or impromptu meetings, are not captured. Researchers have therefore suggested design recommendations for self-monitoring in the workplace that include experience sampling to provide richer insights on productivity [35].

Recently there has been a slight shift to examining productivity more holistically. Meyer et al. has classified what makes a day "good" or "typical" for software developers in terms of productivity, but this was based on one end-of-day survey [34]. Further, a recent classification of personal productivity for knowledge workers shows early evidence that emotional or physical state can influence perceived productivity [21].

Instead of strictly aiming to measure and increase productivity, we posit that TWS is a step towards an alternative, holistic evaluation that could eventually become a standardized measure of performance for knowledge workers. In order for participants to deeply reflect on their personal concept of Time Well Spent, they need to reflect on all the activities they do during a day and have a sense of whether or not they spent that time well. Further, since it's not currently possible to have an automatic summary of activities and reflections, we set out to collect self-reported experience samples.

\section{Stress and Interactive Technologies for Well-Being}

Stress is a part of life for many adults, especially in the workplace. A 2019 survey by the American Psychological Association found that $64 \%$ of adults identify work as a major source of stress [2]. In the HCI community, stress has been addressed in many aspects of knowledge work, such as multitasking [32], email [31], and distractions [27]. More generally, emotions directly influence how we perform everyday tasks, interact with others, learn, work, and make important decisions [24]. Negative emotions are known to affect our physical and mental well-being, and a higher positive affect balance has been correlated with higher productivity [26]. Since worker mental well-being influences performance and productivity, there is an effort to combat mental health concerns.

Beyond tracking work behaviours, self-monitoring technologies are used for a variety of health behaviours including tracking physical activity [8, 9, 23, 13], emotional states [33], stress [31,30], sleep [20], and diet [14]. The goal of these technologies is to increase self-awareness which, according to the Transtheoretical Model, may eventually lead to behaviour change [39]. Our long-term goal is to extend these tracking tools and incorporate a more holistic thinking about time at work in order to build awareness and hopefully lead to behaviours that balance productivity and well-being.

\section{STUDY - CAPTURING HOLISTIC THINKING}

The main goal of our study was to examine whether the concept of TWS can capture holistic thinking about knowledge work. Ultimately, we wanted participants to answer the question 'What is Time Well Spent?'. However, from piloting, this concept was too difficult for participants to come up with a thoughtful answer when reflecting abstractly. To have participants deeply reflect on the concept and produce a thoughtful personal definition of TWS, we performed a multi-day experience sampling study instead of a single survey or interview.

\section{Participants}

We recruited 40 workers (21/19 M/F; ages 22-50, $\mathrm{M}=28.2$, $\mathrm{SD}=5.71)$ through word-of-mouth and an online public study 
posting board at a local university. They worked in 13 different positions: actuarial analyst (1), archaeologist (1), administration/assistants (7), engineers (3), financial analysts (2), grad students (10), managers (4), marketing strategists (1), researchers (3), salespeople (2), social worker (1), software developers (4), and writer (1). We limited the number of participants from any one field to 10 . The inclusion criteria was that they worked full-time with at least 6 hours per working day, the majority of that time was spent using technology, and the individual must have some autonomy on the tasks they choose to perform throughout the day. Participants gave informed consent and were compensated with a \$40 CAD gift card.

\section{Procedure}

Our main objective in the study procedure was to collect personal definitions of the concept of TWS. Therefore, we asked participants in a TWS survey "Over the past workweek, you have been reflecting on how you have been spending your time. How would you define 'Time Well Spent'?" In designing the procedure for this study, we found we had to add reflective insitu activities for participants because we wanted them to think about the concept of TWS and about whether their time was well spent or not over a period of time. While this reflection and in-situ data collection of activities during primary working hours took up a majority of the study, our main goal was for this to prompt participants to provide a thoughtful definition of the concept of TWS. To reinforce the holistic nature of this study, we did not mention the term 'productivity' at any point. Whenever the term was mentioned by participants in the survey responses, it came from them without prompting.

Overall, the study consisted of an initial survey, 5 days of hourly experience samples and daily end-of-day experience samples, the TWS survey, and a follow-up survey. In the initial survey, participants set up the experience sampling parameters, which included the days of their work week, the time of day they should begin receiving notifications in order to complete at least 4 experience sampling surveys each day, and whether they wanted to receive reminders by text message or email.

For the 5 days of hourly experience samples, participants were asked to complete an online experience sample survey every working hour. Each survey prompted the respondent to "Please reflect on the time since your last survey, or since the beginning of your workday. What personal and work activities did you engage in?". We provided a list of examples to reinforce that we wanted them to reflect on all activities, including non-work activities such as breaks, face-to-face or online communication, interruptions, or any other personal activity. We then asked 3 questions: (Q1) "How do you feel about how well you have spent your time?" This was rated on a 9-point Likert scale with a neutral face at 5, frowns below 5, and smiles above 5 (see Figure 1). We found that pilots responded better to these faces than numbers or 'how well' descriptions; (Q2) "Why do you feel this way?" Open response; (Q3) "How did you spend your time?" Open response.

In addition, we asked participants to complete an end-of-day survey to rate their day as a whole and note whether it was a typical day or not and why. They also received a text message or email at the end of the day, letting them know how many

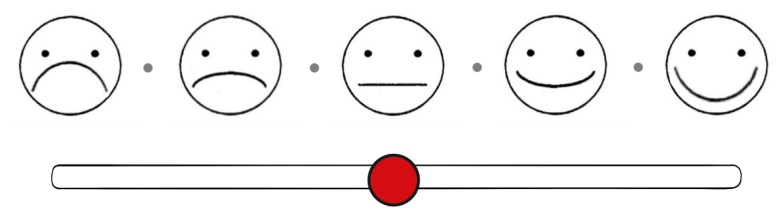

Figure 1. Five $(1,3,5,7$, and 9$)$ of the nine faces in the Likert scale, lined up with their position on the slider. In the survey, participants saw one face and the shape of the mouth changed with the slider.

days of tracking they had left to complete. The experience sampling finished when the participant had completed 5 days of surveys (at least 4 completed surveys per day).

In the TWS survey, at the end, we asked participants for their personal definition of the concept of TWS. Additionally, we asked about participants' own characterization of their workplace environment and demographics. After two weeks, we sent optional informal follow-up emails asking about the experience of the study and the impact of the reflection itself.

\section{Data Collection and Analysis}

For the experience samples, we sent participants a text message or email notification every hour. For sending the notification, we created a simple Python messaging server using Python's smtplib module [41] and Twilio [44], a communication API. To capture the samples we used Qualtrics surveys. For the initial and TWS survey we also used Qualtrics.

The 40 participants each provided a final definition of TWS. To analyse and code these 40 definitions, we performed a two-step process involving three authors. First, to inform the final coding of the definitions, two authors chose a random subset of 300 of the collected experience samples and independently coded them for explanations of the ratings following a thematic analysis approach [6]. The codes were discussed and consolidated, and saturation was reached. Second, one of these authors and a third author then used the previously identified codes as a basis for coding the 40 TWS definitions. For this coding, the two authors used thematic analysis and independently coded a subset of the definitions (20 entries; 50\%) and discussed them. This step served to refine the original set of codes, mostly their descriptions, and to generate higherlevel themes. Most TWS definitions were multi-coded as they touched on more than one theme. The full set of 40 were coded by the lead author after the agreement was reached.

After coding the TWS definitions, one author went back and coded all 1149 hourly surveys to validate the identified highlevel themes of TWS and to assess whether experience sample explanations of TWS ratings were work and results-focused or focused on the state and well-being of the participant.

\section{RESULTS}

We report the study results in three parts: descriptive statistics of the experience sampling, characterization of personal definitions of TWS, and insights from the hourly self-reports.

\section{Descriptive Statistics}

We collected 1321 experience samples (1149 hourly surveys, 172 end-of-day surveys) from 40 participants (average of 33.0 


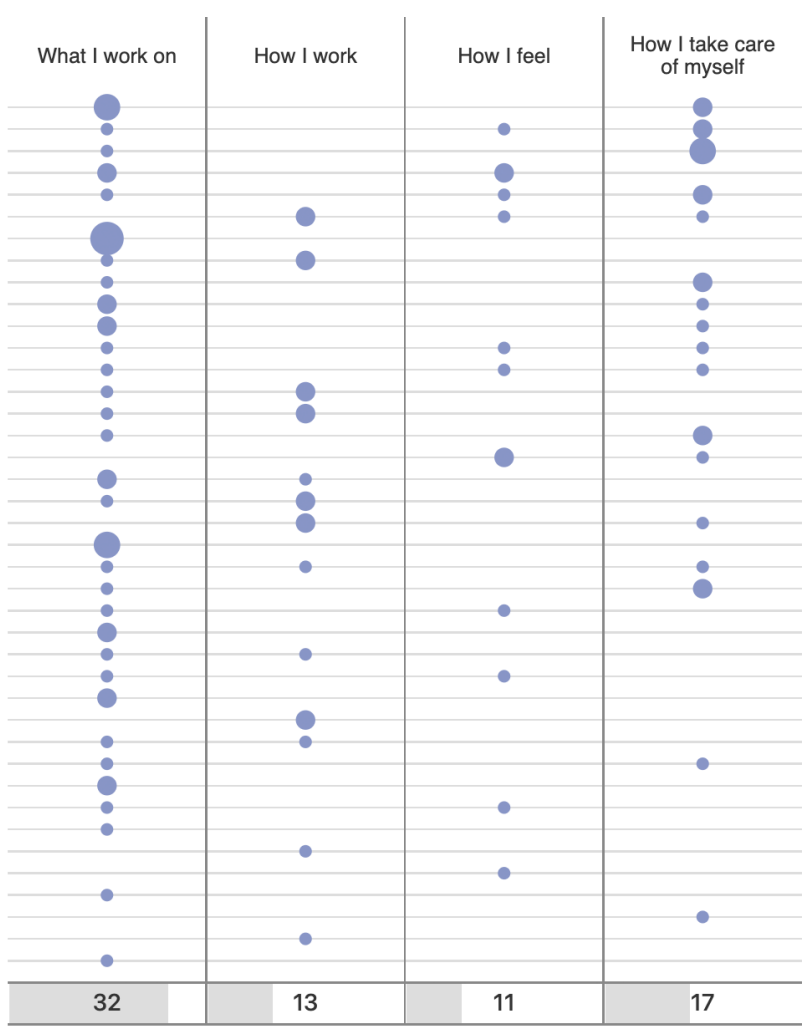

Figure 2. Participants $(n=40)$ each gave a definition of TWS, which is represented by a line. It could be multi-faceted in terms of touching multiple major themes (multiple circles across the line) and multiple subthemes within a theme (size of the circle). The number at the bottom gives the total number of participants (out of 40) who touched on the corresponding major theme.

per participant). On average, the study took 5.5 unique working days spanning an average 8.7 calendar days, per participant. The definitions of TWS collected in the TWS survey ranged in length from 3 to 90 words $(M=28.7, S D=20.2)$.

\section{Characterizing TWS During Primary Working Hours}

From the 40 TWS definitions we identified 15 subthemes of TWS and grouped these under 4 larger themes. Figure 2 shows that the distribution of these codes differed for each participant. We next discuss the themes and subthemes.

What I work on. Since we asked about TWS during primary working hours, it is not surprising that 32/40 definitions had a results-focused dimension of work. We found that some participants valued progress, while others valued completion of tasks or a mix of both. Participants who listed progress as an important component of TWS often talked about their progress in the context of a larger goal, e.g. "I consider time to be managed well when I have finished all the tasks I had on my to-do list by the end of the day. I create my to-do list based on larger projects, so that means I'm closer to completing my long-term goals everyday." (P34). They felt their time was better spent on tasks that push them towards finishing a larger project than menial day-to-day tasks or unrelated administrative work. Completion of tasks was usually in regards to tasks that could be completed in one day rather than a larger project. On a similar note, many participants also recognized that they followed either a long-term or short-term plan and that their time is well spent when they work according to this plan. Participants also cared about the quality of work they performed. They explicitly stated that their time is well spent when they are doing their best work and producing high quality results, e.g. "providing quality customer service" (P39).

How I work. The subthemes of punctuality, efficiency, and mental focus describe the person-focused working behaviour valued by 13 out of 40 participants. For punctuality, participants mentioned both external deadlines ("Meeting my deadlines and staying on top of my paperwork." (P25)) and self-imposed requirements ("Getting tasks done in a timely manner" (P10)). Efficiency-focused participants were concerned about using time as efficiently as possible. This is different, but not mutually exclusive from valuing mental focus, staying focused on a task for long, uninterrupted periods of time and avoiding distractions. For example, P5 defines TWS as "time spent focused and attentive to my work".

How I feel. 11/40 definitions captured some aspect of feelings, expressed in the form of a sense of satisfaction or achievement, the feeling of doing something meaningful or fun, or the avoidance of feeling guilt about how they spent their time. Those expressing satisfaction or achievement talked about satisfaction in the work they produced or the way they worked. For example, P9 defined TWS as time "when I felt satisfied that I used my abilities adequately”. Recognizing meaningful and fun meant valuing the importance or enjoyment of the work itself. For example, P1 felt time was well spent when the tasks were worth their attention, e.g. "I would define it as time spent on things/tasks that I feel are worth my attention.", and P21 listed "having fun" as one component of their definition.

How I take care of myself. 17/40 definitions mentioned activities that are not specifically work related. These fell into 4 major categories: physical health, mental and emotional health, social bonds, and breaks from work. During primary working hours, many participants felt it was important to pay attention to their physical health by doing things like eating, moving, or napping, e.g. "Accomplishing many tasks, bonding with co-workers, or getting mid-day breaks to move and walk" (P6). Some participants prioritized their mental and emotional health and noted that taking time to care of this aspect of their health was important and well spent. Maintaining relationships and social bonds was also important for many participants, in their personal life but many also explicitly valued nurturing social bonds with colleagues. For example, P19 explains "time spent socializing is also enriching, as long as it doesn't take up too large a portion of a workday.” Breaks from work were valued, but often had caveats, such as being necessary, well-placed, or short.

\section{Hourly Reflections on TWS}

While the main focus of this study was to collect personal definitions of the concept of TWS, we also analyzed the 1149 hourly experience sample answers to the question Why do you feel this way? to determine whether participants explain their rating using work and results-focused language (What I work on and How I work) or using well-being and emotionallydriven language (How I feel and How I take care of myself). 
Similar to the TWS survey responses, the majority of the hourly experience samples (955 of 1149) focused on the work output and how the participant worked. These samples further supported our identified themes and subthemes and captured all dimensions of 'What I work on', e.g. "Accomplished tasks that needed to get done. Tasks were not demanding." (P2), "Got my code working." (P7), all the way to the ones of the 'How I work' theme, for instance with a participant stating "I was working throughout the whole hour with almost no distractions on an important task I know I had to get done, and got the code to work." (P32).

Also in line with the TWS analysis, there were a notable number of samples (265/1149) that also captured the 'How I feel' and 'How I take care of myself' theme. Some examples of emotionally-driven answers include "I am really proud of myself for staying on task" (P31), "I was angry because I did a job from another department" (P23), and "felt good to be needed and to have valuable input" (P4), while explanations using physical state included "I felt tired and exhausted at the end of the day!" (P17), "not physically feeling as great today" (P38), and "Felt energized even though it was Monday morning" (P30). It is not surprising that most explanations for rating TWS were based on results-focused work since we were polling during the work day; many of the entries that mentioned emotional or physical state also mentioned work. Importantly, there is notable variation in the total number of emotional or physical state-based explanations between participants. The total number of these entries per participant ranged from 0 to $18(\mathrm{M}=6.63, \mathrm{SD}=5.07)$ and the total percentage of these entries per participant ranged from $0 \%$ to $85 \%(\mathrm{M}=$ $18.92 \%, \mathrm{SD}=24.08 \%$ ). This suggests substantive individual differences among participants in terms of the emphasis on emotional and physical state as a component of TWS.

\section{Impact of the Experience Sampling}

Based on informal conversations with participants directly afterwards, we were given the impression that some participants were affected by the act of recording the hourly reflections. Thus, two weeks after the study finished we sent optional feedback emails asking "In what way, if at all, was reflecting on Time Well Spent helpful or unhelpful?" We received 15 responses and found that 3 participants who had already been satisfied with the way they spent their time during primary working hours did not find the act of self-reflection every hour in this study to be helpful, rather they found it to be "tedious" (P3) and "interruptive" (P1). Meanwhile, there were 7/15 participants who reported changing their feelings towards work because of the reflection and 6/7 of these participants gave at least $25 \%$ emotion-based explanations for their TWS ratings. For example, one participant felt guilty he was taking too much time during the workday to talk with his long-distance partner (necessitated by the time difference), but during the study he realized this social and emotional connection was important for his ability to work and that he was working enough atypical hours to not feel guilty anymore. Another participant noted "after my week long survey with this study, I was cheery to realize that I feel 'mildly happy' during most of my work hours and I wasn't as depressed as I thought I was." (P39). $5 / 15$ participants were neutral towards the study. They did not find it annoying, but they only gained small insights and would not use the tool in the future.

\section{DISCUSSION}

We have made progress at capturing a more holistic concept of work. We found that by using the term Time Well Spent, knowledge workers think more holistically about their work, combining traditional productivity-related concepts with wellbeing. In recent and the most closely related work, Kim et al. have already shown that 'productivity' is a multifaceted concept and provide early evidence that emotional or physical state can influence perceived productivity [21]. With 'Time Well Spent' we introduce a different concept that encompasses productivity dimensions, yet captures a more personal assessment of how one spends one's time against one's values, and is not limited to any defined set of activities. More specifically, our thematic classification showed that TWS: (1) introduces a strong theme of Self Care (acknowledged by 17/40 participants); and (2) relative to [21], significantly emphasizes the theme of Emotions and feelings (in 11/40 definitions). Our frequency counts illustrate the pervasiveness of these wellbeing-related aspects. Especially in today's knowledge work environments in which mental health concerns come more into the fore, the more holistic concept of TWS can provide many benefits, for example, for assessing one's work.

To examine TWS at work and gather thoughtful and wellreflected definitions of it, we used a method that differed from other studies, such as the one by [21], in key ways. To have participants deeply reflect on their work and the TWS concept, we first had participants self-reflect on it for a 5 day period, asking them to $\log$ all activities during primary working hours, asked for a TWS (Likert) rating of it and an explanation of their rating. Only after the 5 day reflection period, we asked participants for their personal definitions of TWS. In comparison, Kim et al. [21] focused on productivity in work and life by having participants log "productive activities" during all hours and asking how productive the activity was and for an explanation, rather than thinking more holistically about work and TWS during working hours. Our piloting demonstrated how valuable this additional period and holistic self-reporting was for participants to come up with a thoughtful answer when reflecting abstractly.

We posit that the use of reflection on TWS can provide benefits to knowledge workers that go beyond an awareness change of productivity at work and generally lead to a healthier and more emotionally-aware workforce. Self-monitoring and reflection have already been shown to provide benefits for certain areas, especially in the health domain (e.g., [8]), and also for productivity (e.g., [21]). In our study, we saw preliminary evidence that some participants who reflected on TWS had changes in their awareness and perception of their work, such as feeling less guilty and happier, a first step in behaviour change [39]. However, frequent self-reports and explicit reflection on emotions can also be seen as tedious and have negative effects for some individuals. Consistent awareness of negative emotions may highlight these and make the individual feel worse. As seen in [27], individuals who already have high self-control may feel more stressed by reflecting on activities throughout 
the day. In our follow-up, we found that participants who already felt satisfied with the way their time is spent at work were concerned that a tracking tool would make them feel worse about work. On the other hand, for participants that started the study off dissatisfied with the way they spent their time, the self-reflection appeared to be more helpful. In future work when designing an intervention, it will be important to take into account the satisfaction of participants with their work and pay attention to negative feelings.

In terms of intervention, our preliminary evidence of reflection on actions and feelings causing a change in thoughts has led us to consider Cognitive Behavioural Therapy (CBT) methods. CBT is based on the concept that while experiencing every situation, one's thoughts, feelings, and behaviours are interacting and influencing each other. A CBT-like method with explicit reflection on TWS that encompasses emotions and possible dissatisfactions or other feelings in addition to behaviours/activities may be the missing link for changing the way people think about how they spend their primary working hours. We think a CBT-inspired TWS intervention is a promising next step for this work.

In terms of tracking tools, in current tools like RescueTime [40], productivity is quantified through a combination of labeling activities as productive or not and measuring the amount of time spent on each activity. Tools like this are exceptional at this basic level of tracking, easily providing the user with visualizations, text analysis, and trends. We can and should rely on these tools to do the laborious parts of tracking, but for these tools to work more holistically, humans will need to contribute and reflect on their feelings, thoughts, and personal beliefs. A possibility for extending current productivity-based time tracking tools is to introduce lightweight self-monitoring and simulate a CBT-like method. Every once in a while a reflection could be triggered asking the user to reflect more holistically on whether the time was well spent and their feelings with respect to the tracked activities.

\section{Study Limitations}

Our focus was on characterizing TWS as a holistic concept, therefore we deliberately omitted any mention of 'productivity' in our study method. Asking participants to compare between TWS and productivity may enable us to more directly tease apart the differences, but there could be challenges when comparing between two abstract terms, especially when 'productivity' has been shown to be a complex concept. Extending the scope of the study to the entire day (beyond primary working hours) and involving more types of workers is worth exploring. Our research only captures 40 definitions from across 13 different occupations of knowledge workers, thus the themes are not likely exhaustive. However, our results are sufficiently promising to see if using the concept of TWS in conjunction with an intervention, might influence workers' awareness of how they are spending their time. The hourly ESM can be tedious and can cause survey fatigue, thus exploring alternate data collection methods or time windows may be valuable. Despite the fatigue, all participants in our study were engaged and completed the required samples.

\section{CONCLUSION}

In this paper, we report on an experience sampling study $(n=40)$ that provides a preliminary characterization of Time Well Spent, and shows empirical evidence that the term TWS captures a more holistic notion of work. As we think about the holistic re-design of current productivity and time tracking tools to support the modern knowledge worker's needs, we envision highlighting the integration of emotion tracking and the need for human self-reflection in addition to automatic tracking. This paper brings us one step closer to not only a more holistic, realistic, and standardized measure of work performance for knowledge workers, but also a healthier and more emotionally-aware workforce. Today's information age provides us with a multitude of personal and professional technologies that greatly assist us in our work, but often at the cost of increased stress. A holistic way of thinking about time at work moves us to having our technology working for us instead of against us.

\section{ACKNOWLEDGMENTS}

We are grateful for funding from NSERC Highly Personalized User Interfaces (RGPIN-2017-04549), ABB Industrial Research Grant F17-05273-22R77358, and NSERC CRDPJ 530226-18. We thank all our participants, Michael Oppermann, the anonymous reviewers and Danielle Lottridge for their extremely helpful feedback.

\section{REFERENCES}

[1] American Psychological Association. 2019a. Mental health issues increased significantly in young adults over last decade. (15 3 2019). https://www. sciencedaily.com/ releases/2019/03/190315110908.htm.

[2] American Psychological Association. 2019b. Stress in America: Stress and Current Events. Stress in America Survey. (2019). https://www. apa.org/news/press/ releases/stress/2019/stress-america-2019.pdf.

[3] Arnold B Bakker and Matthijs P Bal. 2010. Weekly work engagement and performance: A study among starting teachers. Journal of occupational and organizational psychology 83, 1 (2010), 189-206.

[4] Jelmer P. Borst, Niels A. Taatgen, and Hedderik van Rijn. 2015. What Makes Interruptions Disruptive?: A Process-Model Account of the Effects of the Problem State Bottleneck on Task Interruption and Resumption. In Proceedings of the 33rd Annual ACM Conference on Human Factors in Computing Systems (CHI '15). ACM, New York, NY, USA, 2971-2980. DOI :

http://dx.doi .org/10.1145/2702123.2702156

[5] Petra M Bosch-Sijtsema, Virpi Ruohomäki, and Matti Vartiainen. 2009. Knowledge work productivity in distributed teams. Journal of Knowledge Management 13, 6 (2009), 533-546.

[6] Virginia Braun and Victoria Clarke. 2006. Using thematic analysis in psychology. Qualitative research in psychology 3, 2 (2006), 77-101.

[7] Derek Clements-Croome and Yamuna Kaluarachchi. 1999. Assessment and measurement of productivity. In 
Creating the productive workplace. CRC Press, 151-188.

[8] Sunny Consolvo, Predrag Klasnja, David W. McDonald, Daniel Avrahami, Jon Froehlich, Louis LeGrand, Ryan Libby, Keith Mosher, and James A. Landay. 2008a. Flowers or a Robot Army?: Encouraging Awareness \& Activity with Personal, Mobile Displays. In Proceedings of the 10th International Conference on Ubiquitous Computing (UbiComp '08). ACM, New York, NY, USA, 54-63. DOI : http://dx . doi .org/10.1145/1409635. 1409644

[9] Sunny Consolvo, David W. McDonald, Tammy Toscos, Mike Y. Chen, Jon Froehlich, Beverly Harrison, Predrag Klasnja, Anthony LaMarca, Louis LeGrand, Ryan Libby, Ian Smith, and James A. Landay. 2008b. Activity Sensing in the Wild: A Field Trial of Ubifit Garden. In Proceedings of the SIGCHI Conference on Human Factors in Computing Systems (CHI '08). ACM, New York, NY, USA, 1797-1806. DOI :

http://dx.doi.org/10.1145/1357054.1357335

[10] Mary Czerwinski, Eric Horvitz, and Susan Wilhite. 2004. A Diary Study of Task Switching and Interruptions. In Proceedings of the SIGCHI Conference on Human Factors in Computing Systems (CHI '04). ACM, New York, NY, USA, 175-182. DOI : http://dx.doi.org/10.1145/985692.985715

[11] Laura Dabbish, Gloria Mark, and Víctor M. González. 2011. Why Do I Keep Interrupting Myself?: Environment, Habit and Self-interruption. In Proceedings of the SIGCHI Conference on Human Factors in Computing Systems (CHI '11). ACM, New York, NY, USA, 3127-3130. DOI : http://dx.doi.org/10.1145/1978942.1979405

[12] Nancy G Dodd and Daniel C Ganster. 1996. The interactive effects of variety, autonomy, and feedback on attitudes and performance. Journal of organizational behavior 17, 4 (1996), 329-347.

[13] Thomas Fritz, Elaine M. Huang, Gail C. Murphy, and Thomas Zimmermann. 2014. Persuasive Technology in the Real World: A Study of Long-term Use of Activity Sensing Devices for Fitness. In Proceedings of the SIGCHI Conference on Human Factors in Computing Systems (CHI '14). ACM, New York, NY, USA, 487-496. DOI :

http://dx.doi.org/10.1145/2556288.2557383

[14] Roland Gasser, Dominique Brodbeck, Markus Degen, Jürg Luthiger, Remo Wyss, and Serge Reichlin. 2006. Persuasiveness of a Mobile Lifestyle Coaching Application Using Social Facilitation. In Proceedings of the First International Conference on Persuasive Technology for Human Well-being (PERSUASIVE'06). Springer-Verlag, Berlin, Heidelberg, 27-38. http://dl . acm. org/citation. cfm?id=1986822 . 1986828

[15] J Richard Hackman and Greg R Oldham. 1976. Motivation through the design of work: Test of a theory.
Organizational behavior and human performance 16, 2 (1976), 250-279.

[16] Tristan Harris. 2014. How Tech Could Protect Us From Distraction. Video. (December 2014). Retrieved September 18, 2019 from

https://www.ted.com/talks/tristan_harris_how_better_ tech_could_protect_us_from_distraction.

[17] Barry P Haynes. 2007. An evaluation of office productivity measurement. Journal of Corporate Real Estate 9, 3 (2007), 144-155.

[18] Barry P Haynes. 2008. An evaluation of the impact of the office environment on productivity. Facilities 26, 5/6 (2008), 178-195.

[19] Jing Jin and Laura A. Dabbish. 2009. Self-interruption on the Computer: A Typology of Discretionary Task Interleaving. In Proceedings of the SIGCHI Conference on Human Factors in Computing Systems (CHI '09). ACM, New York, NY, USA, 1799-1808. DOI : http://dx. doi .org/10.1145/1518701.1518979

[20] Matthew Kay, Eun Kyoung Choe, Jesse Shepherd, Benjamin Greenstein, Nathaniel Watson, Sunny Consolvo, and Julie A. Kientz. 2012. Lullaby: A Capture \&\#38; Access System for Understanding the Sleep Environment. In Proceedings of the 2012 ACM Conference on Ubiquitous Computing (UbiComp '12). ACM, New York, NY, USA, 226-234. DOI : http://dx. doi .org/10.1145/2370216.2370253

[21] Young-Ho Kim, Eun Kyoung Choe, Bongshin Lee, and Jinwook Seo. 2019. Understanding Personal Productivity: How Knowledge Workers Define, Evaluate, and Reflect on Their Productivity. In Proceedings of the 2019 CHI Conference on Human Factors in Computing Systems (CHI '19). ACM, New York, NY, USA, Article 615, 12 pages. DOI : http://dx.doi.org/10.1145/3290605.3300845

[22] Young-Ho Kim, Jae Ho Jeon, Eun Kyoung Choe, Bongshin Lee, KwonHyun Kim, and Jinwook Seo. 2016. TimeAware: Leveraging Framing Effects to Enhance Personal Productivity. In Proceedings of the 2016 CHI Conference on Human Factors in Computing Systems (CHI '16). ACM, New York, NY, USA, 272-283. DOI: http://dx.doi .org/10.1145/2858036.2858428

[23] James J. Lin, Lena Mamykina, Silvia Lindtner, Gregory Delajoux, and Henry B. Strub. 2006. Fish'N'Steps: Encouraging Physical Activity with an Interactive Computer Game. In Proceedings of the 8th International Conference on Ubiquitous Computing (UbiComp'06). Springer-Verlag, Berlin, Heidelberg, 261-278. DOI : http://dx.doi.org/10.1007/11853565_16

[24] George Loewenstein and Jennifer S Lerner. 2003. The role of affect in decision making. Handbook of affective science 619, 642 (2003), 3.

[25] Y. Lutchyn, P. Johns, A. Roseway, and M. Czerwinski. 2015. MoodTracker: Monitoring collective emotions in 
the workplace. In 2015 International Conference on Affective Computing and Intelligent Interaction (ACII). 295-301. DOI :

http://dx.doi.org/10.1109/ACII. 2015.7344586

[26] Gloria Mark, Mary Czerwinski, Shamsi Iqbal, and Paul Johns. 2016. Workplace Indicators of Mood: Behavioral and Cognitive Correlates of Mood Among Information Workers. In Proceedings of the 6th International Conference on Digital Health Conference (DH'16). ACM, New York, NY, USA, 29-36. DOI : http://dx.doi.org/10.1145/2896338.2896360

[27] Gloria Mark, Mary Czerwinski, and Shamsi T. Iqbal. 2018. Effects of Individual Differences in Blocking Workplace Distractions. In Proceedings of the 2018 CHI Conference on Human Factors in Computing Systems (CHI '18). ACM, New York, NY, USA, Article 92, 12 pages. DOI : http://dx.doi.org/10.1145/3173574. 3173666

[28] Gloria Mark, Victor M. Gonzalez, and Justin Harris. 2005. No Task Left Behind?: Examining the Nature of Fragmented Work. In Proceedings of the SIGCHI Conference on Human Factors in Computing Systems (CHI '05). ACM, New York, NY, USA, 321-330. DOI : http://dx.doi.org/10.1145/1054972.1055017

[29] Gloria Mark, Shamsi Iqbal, and Mary Czerwinski. 2017. How Blocking Distractions Affects Workplace Focus and Productivity. In Proceedings of the 2017 ACM International Joint Conference on Pervasive and Ubiquitous Computing and Proceedings of the 2017 ACM International Symposium on Wearable Computers (UbiComp '17). ACM, New York, NY, USA, 928-934. DOI : http://dx.doi.org/10.1145/3123024.3124558

[30] Gloria Mark, Shamsi T. Iqbal, Mary Czerwinski, Paul Johns, and Akane Sano. 2016a. Neurotics Can't Focus: An in Situ Study of Online Multitasking in the Workplace. In Proceedings of the 2016 CHI Conference on Human Factors in Computing Systems (CHI '16). ACM, New York, NY, USA, 1739-1744. DOI: http://dx.doi.org/10.1145/2858036.2858202

[31] Gloria Mark, Shamsi T. Iqbal, Mary Czerwinski, Paul Johns, Akane Sano, and Yuliya Lutchyn. 2016b. Email Duration, Batching and Self-interruption: Patterns of Email Use on Productivity and Stress. In Proceedings of the 2016 CHI Conference on Human Factors in Computing Systems (CHI '16). ACM, New York, NY, USA, 1717-1728. DOI :

http://dx.doi.org/10.1145/2858036.2858262

[32] Gloria Mark, Yiran Wang, and Melissa Niiya. 2014. Stress and Multitasking in Everyday College Life: An Empirical Study of Online Activity. In Proceedings of the SIGCHI Conference on Human Factors in Computing Systems (CHI '14). ACM, New York, NY, USA, 41-50. DOI :

http://dx.doi.org/10.1145/2556288.2557361

[33] Daniel McDuff, Amy Karlson, Ashish Kapoor, Asta Roseway, and Mary Czerwinski. 2012. AffectAura: An
Intelligent System for Emotional Memory. In Proceedings of the SIGCHI Conference on Human Factors in Computing Systems (CHI'12). ACM, New York, NY, USA, 849-858. DOI : http://dx.doi.org/10.1145/2207676.2208525

[34] Andre Meyer, Earl T Barr, Christian Bird, and Thomas Zimmermann. 2019. Today was a Good Day: The Daily Life of Software Developers. IEEE Transactions on Software Engineering (2019).

[35] Andre N. Meyer, Gail C. Murphy, Thomas Zimmermann, and Thomas Fritz. 2017. Design Recommendations for Self-Monitoring in the Workplace: Studies in Software Development. Proc. ACM Hum.-Comput. Interact. 1, CSCW, Article 79 (Dec. 2017), 24 pages. DOI : http://dx.doi .org/10.1145/3134714

[36] World Health Organization. 2019. Burn-out an "occupational phenomenon": International Classification of Diseases. (28 5 2019). https:

//www.who.int/mental_health/evidence/burn-out/en/.

[37] Pablo Paredes, Ran Giald-Bachrach, Mary Czerwinski, Asta Roseway, Kael Rowan, and Javier Hernandez. 2014. PopTherapy: Coping with Stress through Pop-Culture. ICST. DOI : http:

//dx.doi.org/10.4108/icst.pervasivehealth.2014.255070

[38] Robert D Pritchard. 1995. Productivity measurement and improvement: Organizational case studies. Greenwood Publishing Group.

[39] James O Prochaska and Wayne F Velicer. 1997. The transtheoretical model of health behavior change. American journal of health promotion 12, 1 (1997), $38-48$.

[40] RescueTime. 2019. RescueTime: Time management software for staying productive and happy in the modern workplace. (2019). https://www. rescuetime.com.

[41] smtplib. 2020. SMTP protocol client. https://docs.python.org/3/library/smtplib.html. (2020). [Accessed January 7, 2020].

[42] April J Spivack and Beth A Rubin. 2011. Spaces to control creative output of the knowledge worker: a managerial paradox?. In Proceedings of the 2011 iConference. ACM, 312-318.

[43] Toon W Taris and Paul JG Schreurs. 2009. Well-being and organizational performance: An organizational-level test of the happy-productive worker hypothesis. Work \& Stress 23, 2 (2009), 120-136.

[44] twilio. 2020. https://www.twilio.com. (2020). [Accessed January 7, 2020].

[45] Steve Whittaker, Vaiva Kalnikaite, Victoria Hollis, and Andrew Guydish. 2016. 'Don't Waste My Time': Use of Time Information Improves Focus. In Proceedings of the 2016 CHI Conference on Human Factors in Computing 
Systems (CHI '16). ACM, New York, NY, USA, 1729-1738. DOI :

http://dx.doi.org/10.1145/2858036.2858193

[46] Thomas A Wright, Russell Cropanzano, and Douglas G Bonett. 2007. The moderating role of employee positive well being on the relation between job satisfaction and job performance. Journal of occupational health psychology 12, 2 (2007), 93.

[47] Despoina Xanthopoulou, Arnold B Bakker, Evangelia Demerouti, and Wilmar B Schaufeli. 2009. Work engagement and financial returns: A diary study on the role of job and personal resources. Journal of occupational and organizational psychology 82, 1 (2009), 183-200. 